\title{
The Terminological Approach to Buddhist Scripture Translation Studies
}

\author{
Jie Zheng ${ }^{1,2}$ Rui Su${ }^{1, *}$ \\ ${ }^{1}$ School of Foreign Languages, Northwest University, Xi'an, Shaanxi 710127, China \\ ${ }^{2}$ School of Foreign Studies, Nanjing University, Nanjing, Jiangsu 210023, China \\ *Corresponding author. Email: sabrina@nwu.edu.cn
}

\begin{abstract}
In order to reveal the influencing factors in the formation of translated terms, this article takes the Buddhist term Sukhāvatī as an example and explores the terminological approach to Buddhist scripture translation studies from the three dimensions of communicative terminology including language, concept and communication. Through the theoretical discussion of these three dimensions, this article constructs a schemata-prototype-instantiations diagram on Sukhāvatī, and demonstrates the vital role played by the host culture in the translation of Buddhist scriptures.
\end{abstract}

Keywords: Terminology translation, Buddhist scripture translation studies, Communicative terminology, Social cognitive terminology, Category.

\section{INTRODUCTION}

The practice of terminology translation in China are intertwined with the four "momentus" stages of translation, namely, ancient Buddhist scripture translation, scientific and technological translation in the late Ming and early Qing dynasties, humanities and social sciences translation in the Republic of China, and contemporary multi-field translation, and the research on terminology translation has developed into a relatively independent subject field until recent years $[1]^{276-}$ 277. Most of the ancient Chinese studies on Buddhist vocabulary focus on common vocabulary and its related language attributes. Those who used Buddhist terminology as the research object include such masters of the Republic of China as Liang Qichao, Chen Yinque, and $\mathrm{Hu}$ Shi and so on. However, due to many factors, the current research on Buddhist terminology in China is scarce. There is still much room for development in the research perspectives and research methods of Buddhist terminology. In terms of the research perspective, case studies of Buddhist word translation are only

*Fund: This paper is supported by phase results of 2021 Special Project of Shaanxi Provincial Foreign Language Discipline - "Ideological and political Teaching Design and Practice of the Translation of Chinese Classics into the English" (No. 2021ND0646). scattered in various documents, and Buddhist studies from the perspective of terminology are even rarer. Chinese research on Buddhist Chinese mainly focuses on Buddhist words as historical materials of Chinese vocabulary (such as studies of Zhu Qingzhi and Fang Yixin). The study of Buddhist scriptures in the translation field mainly explores the history of translation (such as studies of Ma Zuyi and Wang Tiejun), translators [2], and translation theory (such as studies of Chen Fukang, Zhu Zhiyu, Zhu Xiaonong, and Wang Hongyin). As far as research methods are concerned, the study of Buddhist Chinese takes exegetical studies as the mainstream, while the philosophical connotations are mostly found in the fields of religion and philosophy. This "gap between exegetical studies and philosophical connotations" often caused "the insufficient manifestation of the traditional Chinese spirit constructed by the characteristics of Chinese language and of its properties in the humanities of the East and the West" $[3]^{13}$; even if there is discussion that combines exegetical studies and philosophical connotations, rarely seen are in-depth research on how the host culture restricts and accepts the product of this process (that is, the decisive role played by the host culture $\left.[4]^{7}\right)$. In short, the particularity of Buddhist terminology translation and its value to contemporary Chinese translation studies need to be explored urgently. As 
Pan Wenguo [5] $]^{5}$ said: "Our current excavation of this treasure house is not commensurate with the lofty status it deserves".

Sukhāvatī, as the core term of the the Pure-land Sect of Buddhism, has many Chinese translations, which may not be a problem for professionals, but may be difficult to make judgments and choices from the perspective of ordinary audiences. According to Ding Fubao Buddhist Dictionary (2018), Sukhāvatī is transliterated as "Suhefudi (苏 诃缚帝)", "Sumati (须摩提)", "Xu'eti (须阿提)", and paraphrases "(Western) Bliss (World) (西方极乐世界 )", "Western Pure Land (西方净土)", "Amitabha Buddha Kingdom (阿弥陀佛国)", "Peace and Health Preservation (安养)", "Peace and Happiness (安乐)", "Infinite Purity Land (无量清净土)", "Infinite Bright Land (无量光明土)", "Infinite Amitabha Land (无量寿 佛土)", "World of the Lotus Sanctuary (莲花藏世界)", "Pure Land of Vairocana (密严国)", "Pure Land of
Amitabha (清泰国)" and so on. In order to objectively know the acceptance of the above Chinese translated names in the public, the authors conducted searches and statistics on three online databases, CBETA, Dingxiu (Chinese ancient books platform) and Microsoft Bing. All data were retrieved by November the 6th, 2018. The results show that the two Chinese translated terms with the highest word frequency are"极乐世界 (Bliss World)" and "极乐净土 (Pure Land of Ultimate Bliss)" ("Table 1"). In order to facilitate research, the authors further extracted the two key terms "极乐 " and "净土", using communicative terminology and social cognitive terminology as the theoretical basis and research approach to explore the constraints of Buddhist terminology translation and the complexity of the research, hoping to provide new ideas for terminology translation research and Buddhist scripture translation research.

Table 1. The word frequency of Sukhāvatī's Chinese translation

\begin{tabular}{|l|l|l|l|}
\hline \multicolumn{1}{|c|}{ Chinese translation } & Frequency in CBETA & Frequency in Dingxiu & Frequency in Bing \\
\hline 须摩提 & 561 & 31 & 71,200 \\
\hline 须摩题 & 5 & 1 & 21,300 \\
\hline 极乐世界 & 2302 & 300 & 241,000 \\
\hline 极乐净土 & 792 & 31 & 237,000 \\
\hline 西方净土 & 726 & 140 & 39,100 \\
\hline 阿弥陀佛国 & 451 & 14 & 13,100 \\
\hline
\end{tabular}

\section{THEORETICAL DISCUSSION}

Communicative terminology was proposed by Cabré [6] ${ }^{186-187}$. Her representative theory "Theory of Doors" provides a valuable reference for terminology analysis on the epistemological level, thinking that the terminology unit is a polyhedron composed of language (terminology), cognition (concept), and communication (situation). Temmerman [7] extended the methodology of these three dimensions and proposed social cognitive terminology, and he expanded the cognitive dimension to the diachronic dimension, that is, the concept is the cognition that different subjects develop gradually in history, and the communicative dimension is expanded to intercategory information, that is, the viewpoint of other disciplines. This article mainly adopts Temmerman's category description method when analyzing cognitive dimensions, which starts with the classification of the types of understanding units-"entities", "activities" and "umbrella categories". Entities can be defined clearly by using traditional terminology principles, that is, the logical or ontological definition. And activities or umbrella categories are suitable for describing the four types of information using the prototype structure category method to explore the prototype structure of terms: "core definition", "historical information", "intracategorial information" and "intercategorial information" [7] ${ }^{111}$.

The authors chose the two terminological approaches to interpret the Buddhist terminology translation for the following three reasons. First of all, language, cognition and communication have universal applicability for describing the multidimensional nature of terminology units. Secondly, as the climax of Chinese Buddhist scripture translation continued from the Eastern Han Dynasty to the Song Dynasty, homonymic Buddhist scriptural terms reflect the translators and authors' cognition of concepts in a specific social and historical context, and the social diachronic dimension can reflect the evolution of the intellectual history of the discipline. What's more, 
the inter-category information reflects the cognition of the term in other disciplines and can be used to reflect on the interaction between Buddhist terminology and Chinese culture, which is instructive for revealing the host culture's constraints. This paper will discuss the influencing factors of Buddhist terminology translation from the linguistic, conceptual and communicative dimensions.

\section{THREE DIMENSIONS OF THE STUDY OF BUDDHIST TERMINOLOGY TRANSLATION}

\subsection{Linguistic Dimension}

The linguistic research on the dimension of vocabulary is often found in Philology. Starting from etymology, the relationship among form, sound and meaning is explored.

The etymological root of the Chinese character " 乐" can be explained as follows. "乐" is "the general term for five musical scales and eight musical instruments. It looks like the Gupi (鼓鞞) (note: the ' 鼓鞞' is a commonly used musical instrument in the ancient army, referring to the bass drum and the side drum. '木' represents the support of the Gupi.) (Shuowen Jiezi) "Remain in one's proper sphere." (Yi.Xici) ("The country will be peaceful and happy only if there are sufficient daily supplies for scholars, farmers, artisans and merchants") (Taigong.Xialue).

The etymological root of the Chinese character " 净" can be described as follows. It can be traced back to Tang Yun and Ji Yun. The pronunciation is 猙 (Zheng), which means cold. (Kangxi Dictionary)

The etymological root of Sukhāvatī is often interpreted as the feminine form of sukhāvat (full of joy; blissful), which is a combination of sukha (delight, joy) and the affix -vat (full of).

It can be seen from the above discussion that although the Sukhāvatî's translated name "极乐" obscures the feminine meaning of the source language, it seems to be a better option than other translations.

\subsection{Conceptual Dimension}

According to the definitions of quality
dictionaries such as aritannica
(https://www.britannica.com) and Encyclopedia of

Chinese

Buddhism (http://www.chinabuddhismencyclopedia.com), the concepts of Pure Land, Western Paradise and Land of Bliss can be used interchangeably; the book $A$ Dictionary of Chinese Buddhist Terms by Soothill and Hodous, published in 2018, separates "净土" and "极乐" into two entries, and Sukhāvatī is their first corresponding term. The definition of specialized dictionaries has extremely limited interpretation of the term, which is consistent with the premise of Temmerman's [6] ${ }^{118}$ category description method, which is applicable to insubstantial (that is, impossible to perceive objectively) terms, since Sukhāvatī may be an "activity" in the category of thinking or it may be an "umbrella category". Accordingly, this method is used for the conceptual analysis of "乐" and "净 ", the two optional equivalents.

To discover an equivalent more consistent with the essence of Chinese Buddhism, the authors select the "core definition", "inter-category information" and "historical information" about the Western Paradise from the perspective of social cognitive terminology proposed by Temmerman, using his category description method as the theoretical framework to record category information, referring to the writings of the venerable masters of the founder of the Pure-land Sect of Chinese Buddhism. The "inter-category information" relies on the ancient Chinese corpus (http://www.aihanyu.org) and the interdisciplinary content of CNKI. When analyzing data manually, this category description method is not operable because it is only based on the prototype category and lacks the description of secondary concepts. Therefore, this article combines the category schemata-instantiations proposed by Zhang Yihua [8][9] to design the schemata-prototypeinstantiations for Sukhāvatī, as shown in "Figure 1". 


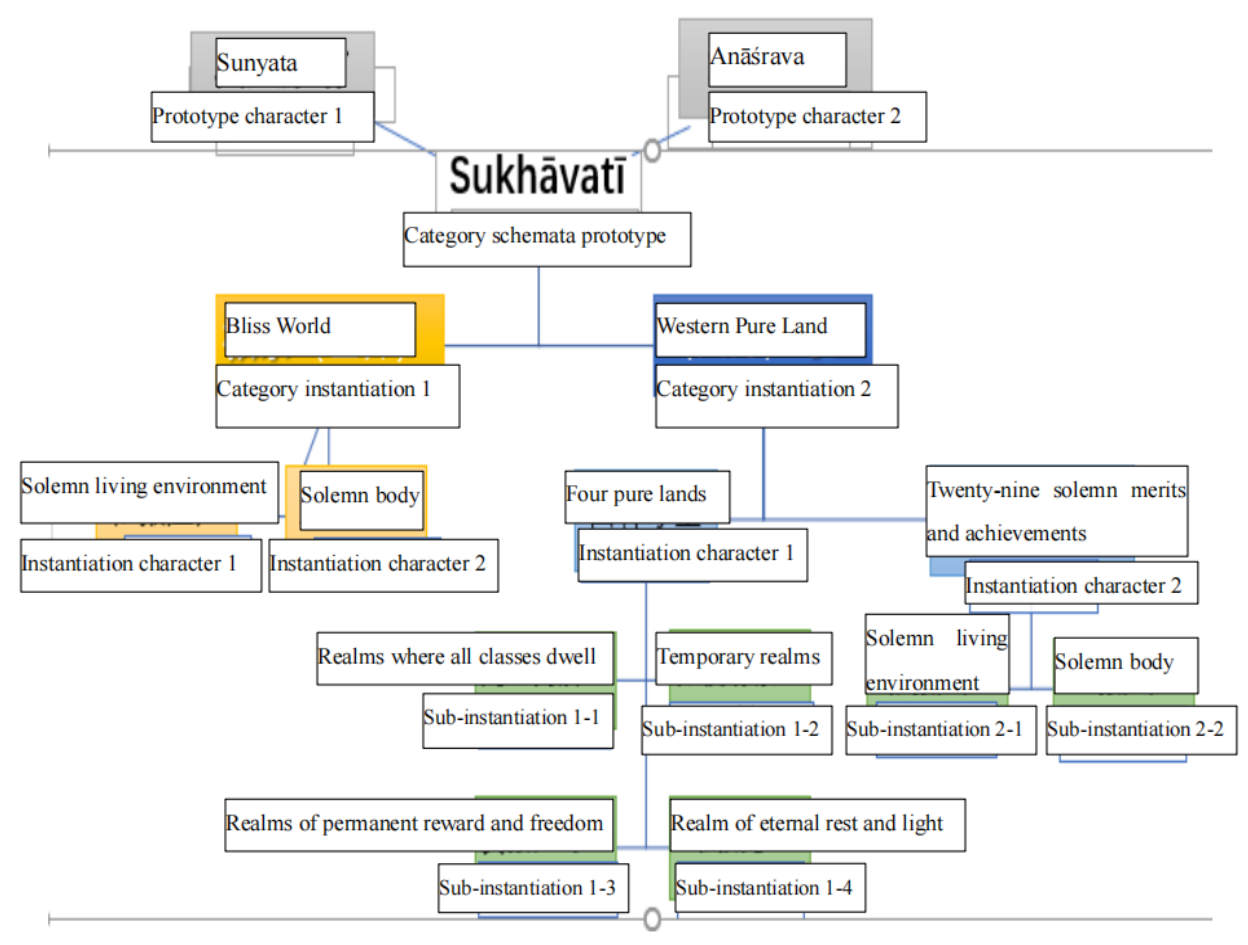

Figure 1 Sukhāvatî's schemata-prototype-instantiations diagram.

Sukhāvatī, as the prototype of the category schemata, has two main category instantiations: "极 乐 (世界)" and "(西方) 净土" (according to the word frequency in "Table 1"). They share the archetype features of "真空妙有 (Sunyata or the void concurrent with wondrous presence)" and "无漏胜相 (Anāśrava, Sanskrit, means to be free from all worries, which is a superb and rare realm)" and so on, and each has its own instantiation characteristics.

The "极乐世界" has two exemplary characteristics: one is the "依报庄严 (solemn living environment)" and the other is the "正报庄严 (solemn body)". According to Volume 1 and Volume 3 of The Commentary and Summary on Amitabha Sutra written by the eighth Patriarch Master Zhuhong of the Pure-land Sect, the "依报庄严 " includes "layers of railings and nets with rows of trees, ponds and pavilions with lotus flowers, heavenly music with rain of flowers, and manifestations of birds with trees in breeze), and the "正报庄严" includes "化主 (Amitabha with light and immeasurable life)", "化伴 (immeasurable and boundless Sravakas and Bodhisattvas) and "众生 (living beings)".
According to Pure-land Sect classics, the instantiation characteristics of "西方净土" are summarized with four types of pure land (the four Buddha-kșetra, or realms) and twenty-nine solemn merits and achievements." The four Buddha-kșetra, or realms are the four Buddha lands named by Zhiyi (the Master Zhizhe of the Tiantai Sect) in the Sui Dynasty ("Although the names of the four Buddha lands were derived from Master Zhizhe, their meanings had long been recorded in Buddhist scriptures") according to the Volume 7 of The Collection of Translation Names. They are "凡圣同 居土 (Realms where all classes dwell), 方便有余土 (Temporary realms), 实报无 (障) 碍土 (Realms of permanent reward and freedom), and 常寂光土 (Realm of eternal rest and light)". The Commentary on Contemplation Sutra used it to interpret the uniqueness of the Western Paradise of Rebirth, that is, all beings were born in four pure lands with different pureness or filthiness. Master Yuanzhao (the sixteenth Patriarch Master of Nanshan Vinaya Sect) once said in the Volume 2 of Commentary on Contemplation Sutra that "being reborn on a kind of Buddha land (that is, the Bliss World) means being reborn on all Buddha lands". Twenty-nine solemn merits and achievements refer to the 
characteristics of the Western Paradise. They were proposed by the ancient Indian Bodhisattva Tianqin (the Sanskrit name was Vasubandhu) in the Upadesha on the Sutra of Amitayus Buddha, including three categories: "The accomplishments of meritorious virtues of the Buddha land, the accomplishments of meritorious virtues of the Buddha, and the accomplishments of meritorious virtues of the Bodhisattva".

The above extracts the connotation of Sukhāvatī based on the core definition and the inter-category information. If one observes its historical information, he or she can see the diachronic characteristics of the Chinese pure land thought, which develops from Zen to the Pure Land in the early days, later from a mixture of various sects with the secret practice of the Pure Land to the single-minded and plain Amituofo Chant after the Song Dynasty, and the influenced believers gradually spread to the ordinary people from influential officials and celebrities. The reason for its evolution was not only the personal learning background of the ancestor, but also had a lot to do with the mainstream Chinese ideology and culture at that time. The first ancestor of Pure-land Sect, Master Huiyuan in the Eastern Jin Dynasty, read six classics at his teenage years, was especially proficient in Zhuang $Z i$ and $L a o ~ Z i$, and inherited Dao An's thought of "equal attention to prajna and Zen method", focusing on the practice of "Buddha Recitation Samādhi" [10] ${ }^{84-85}$. Although the master didn't take a government post, he "had a very intimate relationship with the high rank of the Eastern Jin Dynasty" and "committed to the reconciliation of Buddhism and feudal monarchy, and made outstanding contributions to Buddhism's foothold in the south." [2] ${ }^{85}$ Master Zhiyi of Tiantai Sect in the Sui Dynasty (538-597 AD) "deeply believed in the existence of the Pure Land of Amitabha, often practiced Pratyutpanna Samādhi, and was reborn in praying to Buddha before death" $[10]^{65}$. He said in the Commentary on Contemplation Sutra that "If you want to be reborn into the Bliss World, you must practice the Sixteen Contemplations of Amitabha". Master Shan-tao (613-681 AD) was the second ancestor of the Pureland Sect during the Tang Dynasty. "In the early years, he practiced the Saddharmapundarika Sutra and Vimalakirti Sutra. Later, when he saw the painting of Amita-buddha, he was very happy and yearned for the Western Paradise. So he often concentrates on reciting and practicing the sixteen contemplations of Amitabha according to the methods recorded in the Buddhist scriptures.
Within a few years, he reached a profound state, and in Zen meditation, he saw the attic decorated with jewels, the pond and the golden throne" $[10]^{87}$. During the Zhenguan period of Tang Dynasty, Emperor Taizong of Tang drew lessons from the mass uprising in the late Sui Dynasty, based on agriculture, "attached importance to Confucianism in order to seek the legitimacy of orthodoxy, and respected Buddhism to rebuild spiritual belief." [11] Corresponding to this background, the ideas of "Buddha-recitation" and "Ordinary people was reborn to the Bliss World" advocated by Master Shan-tao "turned the profound and far-reaching temple Buddhism into a wide range of popular beliefs" $[10]^{90-92}$. After the early Song Dynasty, most Buddhism sects concurrently practiced the Pure-land means [12] [13], forming an ideological trend of the integration of the Tiantai and the Pureland, the double practice of Zen and the pure land, and the integration of the pure land and the law. The thirteenth patriarch Master Yinguang (1861 1940 AD) of the Pure-land Sect was proficient in the Tripitaka, but specialized in practicing the chanting method, "From morning to night, he only recited the name of Amitabha" [13] ${ }^{324}$. Born with domestic turmoil and foreign aggression, he advocated the law of cause and effect, and for the urgent task of saving the country and the people, he emphasized the use of Confucianism in the education of the worldly dhammas, and praised more of the Pure-land means in the promotion of dhammas. In short, the historical information of the two terms "极乐" and "净土" reflects the evolution of Chinese Pure-land thought in the context of the times. In this context, the "pureness" meaning of the Chinese character "净 " becomes more prominent.

"极乐" and "净土" both refer to Sukhāvatī. Although the source meaning of the Sukhāvatī is "极 乐", whether it is called "极乐" or "净土", it both means "without all suffering and with all bliss" in Amitabha Sutra. According to the category description method in this section and the schemata-prototype-instantiations diagram, the difference between the two terms is mainly characterized by the instantiation of the four pure lands in the latter, and the division of the four pure lands is based on the pureness or filthiness of beings' karma. In terms of Sukhāvatī, there is no difference. It can be seen that the two are the two sides of Sukhāvatī: "净" (or the pure) is the cause, " 乐" (or the bliss) is the effect, and through the pure, people can feel the bliss; "净" is the body, "乐" is the 
function, and the "净" is manifested by the "乐". As stated in Volume 2 of the Commentary on Amitabha Sutra (Amitabha Sutra Yaojie Bianmengchao): "The happiness of the Pure Land is incomparable and incredible, because there is no suffering as the opposite. In contrast to the extreme suffering in the Saha World, the ultimate happiness of the Pure Land is revealed". As far as Sukhāvatî's ontology is concerned, there is no dual treatment of pureness and filthiness, or suffering and pleasure, and it is in essence the emptiness of dependent origin, and Sunyata or the void concurrent with wondrous presence; but from the feeling of beings, there is a difference between pureness and filthiness, or suffering and pleasure.

According to the above argumentation based on core definitions, inter-category information and historical information, it is sufficient to prove that the Chinese "净" is closer to the connotation of Sukhāvatī. However, this doesn't deny the importance of the Chinese "乐", nor can it explain the reason why the Chinese "极乐世界" has always been at the top of the word frequency list of Chinese translated words.

\subsection{Communicative Dimension}

From the perspective of the inter-category information, "极乐" is a common word in ancient Chinese. It was said in Huainanzi of the Western Han Dynasty, "If you can reach a state without happiness, then there will be no unhappiness; if there is no unhappiness, then you will reach the state of '极乐". "极乐" as a general word generally has two meanings: 1) very happy; 2) enjoy onself thoroughly. The earliest use of "极乐" in the Buddhist scriptures is the in Volume 4 of the translation of Buddha Speaks of Immeasurable Purity Sutra translated by Lokaksema of the Eastern Han Dynasty: "The Buddha said to Maitreya and other Bodhisattvas:' If there is the Buddha in the world, he will be compassionate and he will have mercy on all beings and make all bad things disappear through awesome spiritual power'". Obviously, Lokaksema, who was from Yuezhi ethnicity and was familiar with the Chinese language, borrowed the Chinese vocabulary "极乐" here to compare the feelings of all beings in the Buddhist kingdom. Similarly, "无为 (inaction)", "泥 洹 (death)" and "道 (Tao)" of Taoism are used to compare to Nirvana. Bodhiruci of the Wei Dynasty was inspired by this, and used "极乐" to refer to the Western Bliss World in Buddha Speaks of
Amitabha's Fundamental Secret Mantra Sutra: "Passing from here through hundreds of thousands of millions of Buddhalands to the West, there is a world called Ultimate Bliss". The general word "极 乐" introduced into the Buddhist scriptures by using comparison and analogy methods to explain concepts became a Buddhist term, and then added the meaning of Chinese "极乐", which was widely used in classical literature creation. For example, "I have heard that there is a "极乐世界" in the place where the sun goes down in the Western sky, ten trillion Buddha lands away from China" (The Complete Works of $\mathrm{Li} \mathrm{Bai}$ ). "极乐" is also widely used in modern Chinese because of its rich imagery. For example, "The rise of Bohr theory has brought brilliant brilliance to the entire dark physical sky, making people think that they have seen the beauty of '极乐世界'", "The '极乐世界' that has been lost for a long time since Heisenberg". There are also derogatory usages of '极乐', for example, "In his view, the socialist special economic zone is the '极乐世界' where he pursues pleasure and indulges in dissipation". ${ }^{1}$

Unlike "极乐" that originated in China, the term " 净土" was introduced into China due to the Chinese translation of Buddhist scriptures. Bodhiruci of the Wei Dynasty earlier used the term "极乐净土" specifically to refer to the Amitabha Buddha Kingdom in Buddha Speaks of Amitabha's Fundamental Secret Mantra Sutra. Through a search on the ancient Chinese corpus, it's found that the non-Buddhist classic that used "净土" earlier is The Family Instructions of Master Yan (Yanshi Jiaxun), which directly borrowed this Buddhist term. Most of the meanings of "净土" retrieved by the Bing browser are only Buddhist terms, and rarely have the second meaning of "generally referring to clean places that are not contaminated". Although the "净土" has also entered Chinese literary works due to the Chinese translation of Buddhist scriptures, for example, "The haze grows in '净土', and the moss rises on high towers." (The Complete Tang Poems, or Quan Tangshi) In addition, words "with meaning generated by perfusion" [14], such as "清净 (peace and quiet)", " 净食 (pure diet)", "净瓶 (kalasa)", "净人 (Kiyohito)", "三净肉 (threefold pure meat)", etc., also enriched Chinese rhetoric, for example, "At present, this emerging industry is not a '净土', there is inevitably

1. November 12, 2018, retrieval source: ccl.pku.edu.cn 
a 'dark side'". However, it has always been generally regarded as a Buddhist term and has not been as popular as the native "极乐". The reason is that it is closely related to traditional Chinese cognition. "净" means "cold appearance" in Kangxi Dictionary, while "乐", derived from the original meaning of the general term for five musical scales and eight musical instruments to the meaning of being happy to accept. Fang Litian $[15]^{202}$ believes that "Indian Buddhism talks about 'the nature of the mind is originally pure, but it is contaminated by the world's dust', and Chinese Buddhism says that the nature of the mind is originally enlightened, but it is blinded by delusional thoughts". Scholars such as Luo Anxian and Lin Anwu believe that the concepts of Buddhism's "净 (pureness)" and Confucianism's "敬 (respect)" are different from the Taoist's "静 (quietness)".

\section{CONCLUSION}

The study of Buddhist terminology translation is not only applicable to translation studies and terminology translation - the interaction of the three dimensions of language, concept, and communication, but also has its own particularities. Its particularity is not only due to the intralingual complexity, interlingual complexity, and conceptual multidimensionality of terms of Buddhist scriptures, but also due to the religious particularities of Buddhist scriptures. These particularities lead to the multi-dimensionality of its research methods.

In order to reveal the influencing factors in the formation of terminology translation, this article takes the Buddhist term Sukhāvatī as an example, and explores the terminology approach in translation studies of Buddhist scriptures by using the three dimensions of communicative terminology including language, concept and communication. In the linguistic dimension, the article uses the research methods of philology; in the conceptual dimension, it uses the category description method of social cognitive terminology, and combines Buddhist classics and category relations to interpret the essential connotations of terms; in the communicative dimension, it uses inter-category information to reflect on the constraints of host culture on terminology translation. Through the discussion of the above three dimensions, this article constructs the schemata-prototype-instantiations diagram for Sukhāvatī ("Figure 1"), which can clearly present the essential connotation of the term; on the other hand, this article, through the interactive relationship between the terms "极乐" and "净土" and Chinese culture, verifies what Kong Huiyi [4] ${ }^{7}$ said, that is, the constraint and acceptance of the host culture play a vital role in the translation of Buddhist scriptures.

This article has two main limitations. First of all, in view of the authors' research field and research question, this article doesn't use enough first-hand historical materials to test the corresponding relation between the source language and the target language. As Yao Teng (Associate Professor of the Department of Foreign Languages in Xinzhou Teachers University and a doctoral student at the Xuanzang Research Institute of Northwest University) wrote in his letter to the authors: "according to the studies of Buddhism history, it is questionable whether the equivalents of '极乐世界' that we refer to in the Three Sutras of Pure Land and related scriptures are all translated from Sanskrit". Secondly, in view of the research purpose, this article focuses on the epistemological and methodological aspects to explore the constraints and approach of Buddhist terminology translation, and it just takes the term Sukhāvatī as an example. Therefore, the operability and reproducibility of this example need to be tested and improved in more systematic and in-depth research in the future.

\section{AUTHORS' CONTRIBUTIONS}

Jie Zheng wrote the manuscript, and Rui $\mathrm{Su}$ contributed to revising and editing.

\section{ACKNOWLEDGMENT}

Thanks to Professor Wei Xiangqing, a doctoral supervisor of Nanjing University, Professor Li Li'an, a doctoral supervisor of Xuanzang Research Institute of Northwest University, and Yao Teng, a $\mathrm{PhD}$ candidate of Northwest University, for their guidance and suggestions on this article.

\section{REFERENCES}

[1] Wei, Xiangqing. 2018. Conceptualization and Theorization of Terminology Translation in Humanities and Social Sciences: Some reflections on NUTerm Bank development [J]. Terminology. International Journal of Theoretical and Applied Issues in Specialized 
Communication. 24(2): 262-288. https://doi.org/10.1075/term.00021.wei.

[2] Fang Mengzhi, Zhuang Zhixiang, editor-inchief. (2017). Translators Through Chinese History. Shanghai: Shanghai Foreign Language Education Press. (in Chinese)

[3] Zheng Jixiong. (2017). Name, Character and Conceptual Categories $[\mathrm{J}]$. Journal of Hangzhou Normal University (Humanities and Social Sciences), 39(04):13-28. doi:CNKI:SUN:HSXX.0.2017-04-003. (in Chinese)

[4] Kong Huiyi. (2005). Rewriting a History of Translation. Hong Kong: The Chinese University of Hong Kong Press. (in Chinese)

[5] Pan Wenguo. (2015). Three topics in the study of Buddhist translation - Notes taken at reading Chen Yinke's books. Foreign Language and Translation, (01),5-10+4. doi:10.19502/j.cnki.2095-9648.2015.01.005. (in Chinese)

[6] Cabré M.T. (2003). Theories of terminology: Their description, prescription and explanation. Terminology 9:2. John Benjamins Publishing Company. https://doi.org/10.1075/term.9.2

[7] Temmerman Rita. (2000). Towards New Ways of Terminology Description: The sociocognitive-approach.

Amsterdam/Philadelphia: John Benjamins Publishing Company.

[8] Zhang Yihua. (2017). Lexical Relatedness and Modes of Definition Based on the Prototype and Schema Category Theories: A Case of Categorization-based Definition [J]. Lexicographical Studies, (05): 1-12. doi:10.16134/j.cnki.cn311997/g2.2017.05.001. (in Chinese)

[9] Zhang Yihua. (2017). Defining the Commonalities and Differences Based on the Relation Between Category Schemata and Instantiations: Categorized Lexical Definitions for the English Learner's Dictionary $[\mathrm{J}]$. Foreign Language Teaching and Research,49(02): 240-253. doi:CNKI:SUN:WJYY.0.2017-02-007. (in Chinese )

[10] Shi Daan. (2017). The Course of Pure-land Sect (revised version). Jiujiang: The Pure-land
Sect Culture Research Association of Donglin Temple in Lushan. (in Chinese)

[11] Han Xing. (2017). The Relationship of the Three Religions Under the Discourse of Confucianism in the Early Tang Dynasty [J]. Social Sciences, (12):110-115. doi:10.13644/j.cnki.cn31-1112.2017.12.012. (in Chinese)

[12] Hong Xiuping. (1995). History of Chinese Buddhism Culture. Nanjing: Jiangsu Education Publishing House. (in Chinese)

[13] Jiang Weiqiao. (2004). History of Chinese Buddhism. Shanghai: Shanghai Classics Publishing House. (in Chinese)

[14] Yan Qiamao. (1998). On the "Meaning Generated by Perfusion" in Buddhist Scriptures. Studies on the History of Chinese Language, 160-165. doi:CNKI:SUN:HYUS.0.1998-00-012. (in Chinese)

[15] Fang Litian. (2010). Chinese Buddhism and Traditional Culture. Beijing: China Renmin University Press. (in Chinese) 